UDC: 616.132.2-089.819:616-073.75

DOI: $10.15587 / 2519-4798.2020 .213906$

\title{
TACTICAL AND TECHNICAL ASPECTS OF MINIMALLY INVASIVE LEFT INTERNAL MAMMARY ARTERY - LEFT ANTERIOR DESCENDING ARTERY BYPASS AND HYBRID CORONARY REVASCULARIZATION ON ITS BASIS
}

\author{
O. Pyetkov, I. Polivenok, Yu. Skibo, V. Boyko
}

Reducing surgical trauma is one of the obvious ways of reducing perioperative risks and improving surgical techniques, which is also very positively perceived by patients. Hybrid coronary revascularization (HCR) is one of the ways of minimizing surgical trauma during coronary revascularization.

Objectives: to note the tactical and technical aspects of the minimally invasive left internal mammary artery-left anterior descending artery bypass (mini-LIMA-LAD) and HCR, which allow benefiting from these techniques of myocardial revascularization over the traditional ones.

Materials and methods: Between 2011 and 2019, 39 mini-LIMA-LAD operations were performed at the SI " V. T. Zaycev IGUS NAMSU”. The average age of patients was $60.6 \pm 8.2$ years, 5 (13\%) of patients were female. In nine patients mini-LIMA-LAD was the first (in eight) or second (in one) stage of the planned HCR.

Results and discussion: There were no perioperative deaths, myocardial infarctions or conversions. At a median follow-up time of 49.5 [Q1; Q3: 34.3; 70.6] months one patient died 13 months after surgery. Four patients had angina recurrences at different times. The article discusses the tactical and technical aspects of mini-LIMA-LAD and HCR, which allow benefiting from these techniques of myocardial revascularization over the traditional ones. Conclusions: Mini-LIMA-LAD and HCR on its basis are a low-traumatic alternative to traditional coronary bypass through sternotomy with acceptable early and long-term results. They have a much better cosmetic effect, especially for women, but are more demanding in surgical technique and tissue handling. The strategy of coronary revascularization described, unlike other less traumatic techniques, does not require expensive additional equipment and can be performed by regular means

Keywords: hybrid coronary revascularization, mini-invasive mammary artery-left anterior descending artery bypass, coronary artery stenting, thoracotomy

Copyright (C) 2020, O. Pyetkov, I. Polivenok, Yu. Skibo, V. Boyko.

This is an open access article under the CC BY license (http://creativecommons.org/licenses/by/4.0).

\section{Introduction}

Reducing surgical trauma is one of the obvious ways to reduce perioperative risks and improve surgical techniques [1-3], which is also very positively perceived by patients $[4,5]$. At the same time, less traumatic techniques are accepted for use only if the therapeutic goal is effectively achieved with a reliable result, preferably remote $[6,7]$. The latter is one of the reasons that coronary artery bypass grafting remains a widely used operation, despite the prevalence of interventional procedures $[8,9]$. This is known to be due to two main benefits of coronary artery bypass grafting (CABG) over percutaneous coronary intervention (PCI): no alternatives to the left internal mammary artery (LIMA) as a bypass graft to the left anterior descending artery (LAD) in terms of longevity $[10,11]$ and the relative technical simplicity of CABG compared to complex PCI cases, especially high risk [12-14]. Over time, CABG as such has become less traumatic, although the reduction in the degree of intervention is associated with high demands on the equipment and skills of surgeons [15].

The main areas of injury reduction in $\mathrm{CABG}$ are reduction of incisions up to robotic thoracoscopic interventions [16, 17], rejection of cardiopulmonary bypass (CPB) and manipulation of the aorta [18-20]. Modern technologies already allow for total arterial revascularization with mini-thoracotomy without CPB [21-24].

In recent years, another area of minimizing surgical trauma in CABG is gaining popularity - hybrid coronary revascularization (HCR), which combines grafting of the LAD using the LIMA (mini-LIMA-LAD) and PCI of non-LAD coronary stenoses [25].

Theoretical prerequisites for HCR are the lack of long-term advantages in grafting non-LAD areas, especially using venous grafts, over drug-eluting stents, as well as the mini-invasiveness of the procedure [26].

Modern HCR, initiated in 1996 by G. D. Angelini and co-authors [27], includes thoracoscopic or robotic minimally invasive direct coronary artery bypass (MID$\mathrm{CAB}$ ) and is actively used worldwide [28, 29].

Thus, clinical improvement in an individual patient can theoretically be achieved through the use of different surgical practices, so the principle of informed patient consent to intervention is fully justified, which involves patient participation in decisions about optimal surgical tactics, types and scope of interventions based on his expectations and wishes on the one hand and the capabilities of a particular institution - on the other. However, in practice, the patient is offered the strategy of coronary revascularization, which has developed in a 
particular medical institution. Usually in Ukraine it is PCI or coronary artery bypass grafting via sternotomy with or without CPB [30, 31].

The aim of the work: indicate the tactical and technical aspects of mini-LIMA-LAD and HCR, which allow to obtain the advantages of these methods of myocardial revascularization over traditional.

\section{Materials and methods}

In the period from October 2011 to February 2019 in SI «V. T. Zaycev IGUS NAMSU» 39 mini-LIMA-LAD were performed. The mean age of patients was $60.6 \pm 8.2$ years, among them were 34 men (87\%), 5 (13\%) women. Of these, mini-LIMA-LAD was the first (in eight) or second (in one) stage of the planned HCR in nine patients. The mean age of patients in this subgroup was $62.7 \pm 8.1$ years, among them were eight men and one woman. PCI on non-LAD arteries after mini-LIMA-LAD was performed within two to nine days and included the placement of two (three cases) or one (five cases) stents. During PCI, the functioning of the mammary graft was first checked (Fig. 1). In one patient, mini-LIMA-LAD was performed on the fourth day of acute myocardial infarction without ST segment elevation three days after stenting.

The design of the study was considered by the Committee on Medical and Bioethics SI "V. T. Zaycev IGUS NAMSU" at the planning stage of the study (Minutes No. 8 of 05.10 .2011 ) and recognized as compliant with the principles of the Helsinki Declaration of the General Assembly of the World Medical Association (1964-2000), the Council of Europe Convention on Human Rights and biomedicine (1997), the relevant provisions of the WHO, the International Council of Medical Scientific Societies, the International Code of Medical Ethics (1983) and the laws of Ukraine. Informed consent for additional research and processing of personal data was obtained from patients included in the prospective study.

Mini-LIMA-LAD was performed through an anterior thoracotomy in the $4^{\text {th }}$ left intercostal space $7-9 \mathrm{~cm}$ long (Fig. 2). LIMA was prepared under direct visual control by standard tools (Fig. 3). One-sided pulmonary ventilation was not used. To stabilize the working area of the beating heart, we used the existing pressure-type stabilizer on the rack, which was also used during traditional CABG through sternotomy, and the usual small thoracic retractor, to which the stabilizer was fixed (Fig. 4, 5). CPB and conversions have never been resorted to. The operation was completed by draining the left pleural cavity.

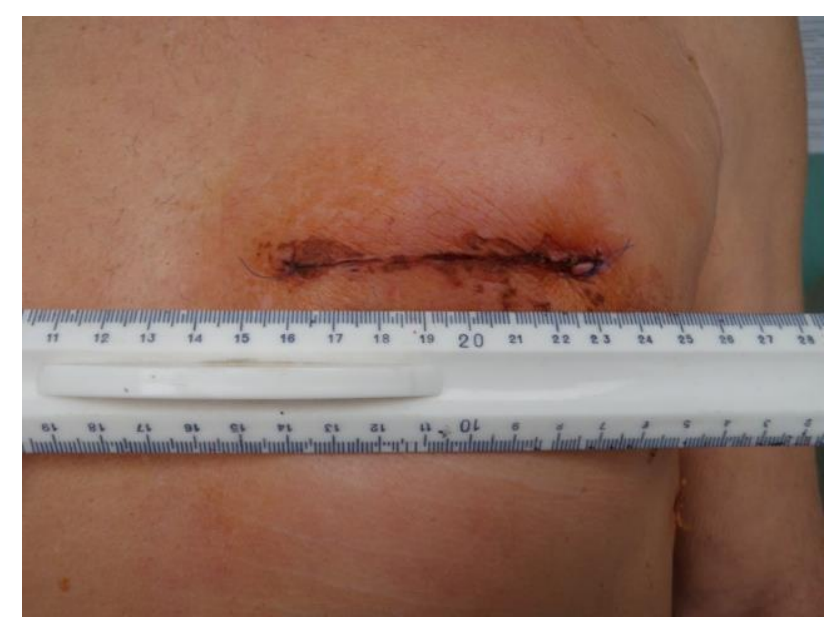

Fig. 2. Appearance of the suture after anterior thoracotomy in 4 intercostal spaces

Categorical data are presented in the form of $\mathrm{n}(\%)$, i. e. the absolute and percentage frequency of occurrence of the trait. Quantitative indicators, distributed according to the normal law, were presented as $\mathrm{M} \pm \mathrm{SD}$ (where $\mathrm{M}$ is the mean value, $\mathrm{SD}$ is the standard deviation); those indicators that are not distributed according to the normal law - in the form of $\mathrm{Me}$ [Q1-Q3], where Me is the median, Q1-Q3 is the interquartile latitude. The normality of the distribution was checked by the Shapiro-Wilkes test. Statistical analysis was performed in the statistical package SPSS V 22.0 for Windows. 


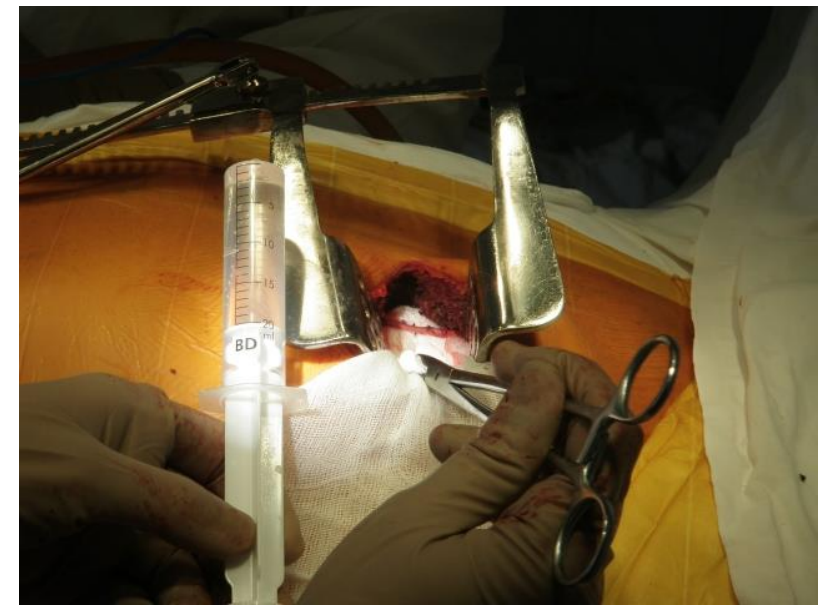

Fig. 3. LIMA in the surgical wound

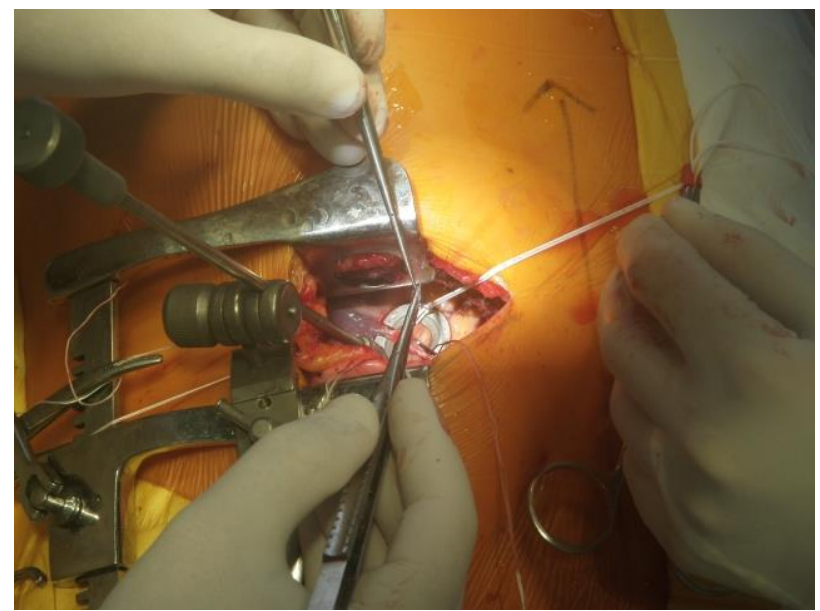

Fig. 4. Positioning of the wound retractor and stabilizer during the LIMA-LAD anastomosing

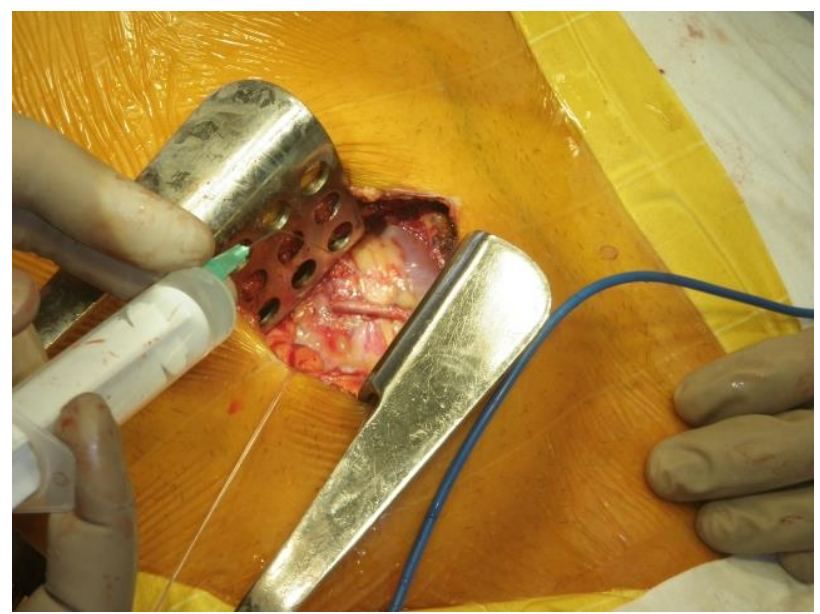

Fig. 5. The final view of LIMA-LAD anastomosis

\section{Research results}

No hospital mortality or perioperative myocardial infarction were observed. The median follow-up was 49.5 [Q1; Q3: 34.3; 70.6] months. One fatal case was observed 13 months after mini-LIMA-LAD for unknown reasons. Recurrences of angina were observed at different times in four patients: in one patient - four years after HCR due to stent occlusion; in two patients -6 months and in the immediate period after surgery, respectively, due to inadequate functioning of the mammary graft; one patient complained of angina pectoris when he consulted a vascular surgeon about abdominal aortic pathology 6 years after HCR, but refused coronary angiography.

The main complication during the postoperative period was poor thoracotomy wound healing - 10 (26\%) cases, but without further complications and long-term consequences. Among these patients, eight had diabetes or obesity. One patient had a left-sided hemothorax $(800 \mathrm{ml})$ on the third day after surgery - the pleural cavity was drained.

\section{Tactical aspects.}

The most common indication for performing miniLIMA-LAD was LAD lesion associated with high potential technical difficulties in performing PCI or expected unsatisfactory long-term outcome (chronic occlusion, massive calcification). In this situation, it is justified to use LIMA to LAD as an "ideal graft", but performing a sternotomy to perfom a single anastomosis seems too traumatic, especially in the eyes of the patient. The lack of alternatives to sternotomy can lead the patient and physician to perform futile or risky PCI attempts, which can lead to unnecessary waste of resources and significantly worsen the situation. Quite different in this situation is the proposal to perform a mini-thoracotomy $7-8 \mathrm{~cm}$ long without CPB. Our experience with patients indicates that the need to cut the bone (sternum) is a significant psychological barrier, and thoracotomy is much easier to perceive.

Quite exotic, but quite real in routine clinical practice, the indication for mini-LIMA-LAD may be the unavailability of special equipment for complex stenting. Consumables for mini-LIMA-LAD are limited to a few units of conventional suture material and means of general anesthesia, other things being equal to PCI, so in Ukraine mini-LIMA-LAD does not look more expensive than PCI with modern drug-eluting stent.

During the second stage of HCR-PCI on "nonLAD" arteries, it is necessary to check the functioning of the LIMA-LAD graft, as this can significantly affect further tactics: inadequate functioning of the graft may require sternotomy. Conversely, with satisfactory graft functioning, if necessary, interventions on the left main coronary artery (LMCA) can be performed with much less risk ("protected LMCA").

The reverse order of HCR, when PCI is first performed, is justified in cases of acute myocardial infarction and in unstable angina, when it is important to restore blood flow in a culprit lesion quickly and with the least risk. In the presence of LAD lesions that affect the course of the disease, but are not subject to stenting, it is justified to conduct a mini-LIMA-LAD. We have observed one such case. In general, it is more justified to perform the first stage of mini-LIMA-LAD, because in this case the operation is not hindered by double antiplatelet therapy, and during the second stage - PCI - the functioning of the graft was checked. Simultaneous execution of both stages during one procedure looks very attractive, however such approach demands existence of a valuable hybrid operating room. 
There is still no consensus in the literature on the order of surgical and interventional stages of HCR, as different combinations that occur in practice give the same result, and the choice of order is determined mainly by the capabilities of the team and the specific clinical situation [32].

In the presence of borderline lesions of RCA or $\mathrm{Cx}$, the so-called "delayed hybrid" revascularization strategy can be applied, by which we mean the implementation of the first stage - mini-LIMA-LAD, and postponed indefinitely (until clinical significance) PCI, if after the first stage there is a disappearance angina and ischemic events, which can be proven by an exercise test. This approach avoids the intervention of excessive volume (grafting of two or more arteries) or costly additional diagnostic tools (fractional flow reserve).

Some issues of surgical tactics relate to rare cases of mammary graft dysfunction during the observation period. We have observed two such cases. One of them was associated with inadequate LIMA placement, which led to deformation of both the LIMA and LIMA-LAD anastomosis. Attempts to stent the anastomosis area were not effective due to the rapid development of restenosis in the stented area. Sternotomy and CABG with two sequential distal anastomoses to LAD - more proximal and distal to the previously anastomosed and stented area - was perfomed.

Technical aspects.

When performing CABG through the anterior mini-thoracotomy, it is necessary to clearly understand the spatial location of the imaginary anastomosis. Usually it is enough to get acquainted with a chest X-ray in direct projection and coronary angiography and examination of the patient. An anterior thoracotomy in the fourth intercostal space on the left usually leads the surgeon to the segment of the LAD approximately in the area of the second diagonal branch (if any) and allows the anastomosis to be placed slightly higher (which is more convenient) or slightly below it. When applying an anastomosis on a beating heart to create a reliable stabilization the anastomosis should be located approximately in the projection of the middle of the wound. This feature should be taken into account when analyzing coronary angiograms and LAD lesions, as there will be almost no space for maneuver during surgery. This refers primarily to multilevel lesions of the LAD when a sequential grafting is advisable, and occlusive lesions of the LAD, when the analysis of the LAD condition is hampered by its weak retrograde filling.

Thus, the second of the two cases of mammary graft dysfunction was associated with underestimation of the LAD condition in the middle and partially distal part with its occlusion in the proximal. Due to the limited space in the wound, LIMA was anastomosed to a segment of the LAD with a small diameter (about $1 \mathrm{~mm}$ ) and with the phenomena of hardening and wall fibrosis. The patient's angina did not regress, and on a control angiography two months after surgery, the LIMA graft looked like it was gradually narrowing to and within the anastomotic area, and the LAD was narrowed to the same extent for about $8-10 \mathrm{~mm}$ distal to the anastomosis. Moreover, balloon angioplasty failed to increase either the diameter of the anastomosis or the LAD lumen distal to it, even under maximum pressure. The patient was reoperated using sternotomy approach, the isolated free segment of right internal mammary artery was anastomosed to the proximal LIMA "end to end", and along the graft sequentially - to the ramus intermediate (which was planned to stent) "side to side" and to the distal part of the LAD "end to side"; angina regressed.

It should be noted that in two cases of re-CABG after mini-LIMA-LAD, we, as expected, did not experience difficulties and obstacles during the performance of sternotomy and performed it normally. At the same time, cardiolysis, identification of the LAD course and the LIMA-LAD block preparation posed certain technical difficulties.

The location of the LAD in relation to LIMA varies considerably and is more difficult to predict. The most inconvenient option is a significant lateral deviation of the LAD running relative to the LIMA running - such an arrangement requires the detachment of LIMA to a significant extent in the proximal direction. Attempts to facilitate this procedure by the retractor spreading leads to unwanted rib fractures, especially in older patients. Moreover, increasing the length of the wound slightly affects the visualization of LIMA and the convenience of its preparation. In such cases, the least traumatic is the mobilization of the upper rib (usually the fourth), which is achieved by dissection of the sternocostal junction, followed by pulling the rib up - this technique allows to visualize a segment of proximal LIMA above the rib and to the next intercostal space. In most cases it is enough.

Another important point is the relative position of the LIMA and the lung, especially in the lateral location of the LAD, when after the anastomosing there is a significant forced lateral deviation of LIMA. An air-filled left lung can significantly tense the graft in such a situation. To avoid this, it is enough to fix the free lateral edge of the longitudinally dissected pericardium to the upper rib, which prevents the movement of the lung towards the graft and the deformation of the latter.

\section{Discussion}

Experience in monitoring wound healing after mini-LIMA-LAD has shown that these wounds are too sensitive to surgical techniques and injuries, as they remain without the main source of blood supply - LIMA and largely the intercostal artery. Therefore, you should not only avoid rib fractures and tissue injuries, but also use the technique of suturing, which maximally preserves blood circulation in the area of the sutures. So, over time we have abandoned continuous sutures anywhere but the skin.

Regarding the PCI stage, from a technical point of view, it does not differ from the usual stenting of the RCA or $\mathrm{Cx}$, which includes careful preparation of plaque, the use of new generations of drug-eluting stents and intracoronary imaging to optimize stenting [33]. Long-term dual antiplatelet therapy, which is required after PCI, can also potentially improve the long-term patency of the LIMA graft [34]. 
In conclusion, $\mathrm{HCR}$, in contrast to the technique of total coronary revascularization through mini approach, which is successfully developing in Ukraine [35, 36], does not include the use of CPB and additional interventions outside the surgical approach; long-term results of the latter are unknown. The closest modern alternative to HCR is complete arterial revascularization through mini approach on a beating heart, but this technique is used only by a few surgeons in the world and is not present in Ukraine. In our opinion, the main factors hindering the wider use of mini-LIMA-LAD and HCR in Ukraine are overestimation of the cost/benefit ratio, insufficient understanding of the role of these techniques in clinical practice and their scope, underestimation of their advantages over traditional methods and overestimation of complexity.

Study limitations. The approach to myocardial revascularization described by us adheres to the principle of maximum benefit/cost ratio (where by benefit we mean the most complete and long-lasting myocardial revascularization with minimal medical risks for the patient, and by costs - the general provision of interventions). This approach is in demand in terms of limited resources, which applies to most clinics in Ukraine. But it cannot be universal, because in well-equipped cardiac surgery centers of developed countries there is a possibility of effective revascularization by PCI for complex lesions of the coronary arteries, and total arterial revascularization of the myocardium thoracoscopically or robotically using CPB. These techniques are expected to require expensive equipment, high qualifications and training of operators, but, in the end, their use is related to accessibility to the patient, as well as his preferences. The main thing, in our opinion, in this situation on the part of the doctor - the maximum informing of the patient and a real assessment of possibilities of the center.

Prospects for further research. In light of the constant development of interventional technologies and the improvement of coronary stents, it is important to study the long-term results of interventions for different revascularization strategies: mini-LIMA-LAD compared to LAD stenting, and HCR based on mini-LIMA-LAD compared to traditional $\mathrm{CABG}$.

\section{Conclusions}

Mini-LIMA-LAD and HCR based on it are a low-trauma alternatives to traditional CABG through sternotomy with acceptable short-term and long-term results.

Mini-LIMA-LAD and HCR have a much better cosmetic effect, especially in women, but are more demanding on surgical techniques and tissue handling.

The strategy of coronary revascularization described by us, unlike other low-traumatic techniques, does not require expensive costs for additional equipment and can be performed by regular means.

\section{Conflict of interest}

The authors declare that they have no conflicts of interest.

\section{References}

1. Doenst, T., Diab, M., Sponholz, C., Bauer, M., Färber, G. (2017). The Opportunities and Limitations of Minimally Invasive Cardiac Surgery. Deutsches Ärzteblatt International, 114 (46), 777-784. doi: http://doi.org/10.3238/arztebl.2017.0777

2. Hua, K., Zhao, Y., Dong, R., Liu, T. (2018). Minimally Invasive Cardiac Surgery in China: Multi-Center Experience. Medical Science Monitor, 24, 421-426. doi: http://doi.org/10.12659/msm.905408

3. D’Onofrio, A., Gerosa, G. (2015). Shifting a Paradigm of Cardiac Surgery: From Minimally Invasive to Micro-Invasive. The Journal of Heart Valve Disease, 24 (5), 528-530.

4. Gallego-Poveda, J., Guerra, N. C., Gonzalez-Rivas, D., Carvalheiro, C., Ferreira, H., Sena, A. et. al. (2017). Cardiac surgery using a single thoracic port - current status and future directions. Journal of Thoracic Disease, 9 (4), 898-902. doi: http://doi.org/ 10.21037 jtd.2017.02.07

5. Langer, N. B., Argenziano, M. (2016). Minimally Invasive Cardiovascular Surgery: Incisions and Approaches. Methodist DeBakey Cardiovascular Journal, 12 (1), 4-9. doi: http://doi.org/10.14797/mdcj-12-1-4

6. Doenst, T., Lamelas, J. (2017). Do we have enough evidence for minimally-invasive cardiac surgery? A critical review of scientific and non-scientific information. The Journal of Cardiovascular Surgery, 58 (4), 613-623. doi: http://doi.org/10.23736/S00219509.16.09446-5

7. Easterwood, R. M., Bostock, I. C., Nammalwar, S., McCullough, J. N., Iribarne, A. (2018). The evolution of minimally invasive cardiac surgery: from minimal access to transcatheter approaches. Future Cardiology, 14 (1), 75-87. doi: http://doi.org/10.2217/ fca-2017-0048

8. Melly, L., Torregrossa, G., Lee, T., Jansens, J.-L., Puskas, J. D. (2018). Fifty years of coronary artery bypass grafting. Journal of Thoracic Disease, 10 (3), 1960-1967. doi: http://doi.org/10.21037/jtd.2018.02.43

9. Diodato, M., Chedrawy, E. G. (2014). Coronary Artery Bypass Graft Surgery: The Past, Present, and Future of Myocardial Revascularisation. Surgery Research and Practice, 2014, 1-6. doi: http://doi.org/10.1155/2014/726158

10. Tatoulis, J., Buxton, B. F., Fuller, J. A. (2004). Patencies of 2,127 arterial to coronary conduits over 15 years. The Annals of Thoracic Surgery, 77 (1), 93-101. doi: http://doi.org/10.1016/s0003-4975(03)01331-6

11. Otsuka, F., Yahagi, K., Sakakura, K., Virmani, R. (2013). Why is the mammary artery so special and what protects it from atherosclerosis? Annals of Cardiothoracic Surgery, 2 (4), 519-526. doi: http://doi.org/10.3978/j.issn.2225-319X. 2013.07.06

12. Ahn, J.-M., Park, D.-W., Lee, C. W., Chang, M., Cavalcante, R., Sotomi, Y. et. al. (2017). Comparison of Stenting Versus Bypass Surgery According to the Completeness of Revascularization in Severe Coronary Artery Disease. JACC: Cardiovascular Interventions, 10 (14), 1415-1424. doi: http://doi.org/10.1016/j.jcin.2017.04.037 
13. Head, S. J., Milojevic, M., Daemen, J., Ahn, J.-M., Boersma, E., Christiansen, E. H. et. al. (2018). Mortality after coronary artery bypass grafting versus percutaneous coronary intervention with stenting for coronary artery disease: a pooled analysis of individual patient data. The Lancet, 391 (10124), 939-948. doi: http://doi.org/10.1016/s0140-6736(18)30423-9

14. Iqbal, M. B., Ilsley, C., De Robertis, F., Lane, R., Kabir, T., Bahrami, T. et. al. (2017). Comparison of Outcomes of Coronary Artery Bypass Grafting Using Internal Mammary Graft Versus Percutaneous Coronary Intervention for Isolated Proximal Left Anterior Descending Narrowing. The American Journal of Cardiology, 119 (5), 719-726. doi: http://doi.org/10.1016/j.amjcard.2016.11.031

15. Itagaki, S., Reddy, R. C. (2013). Options for left internal mammary harvest in minimal access coronary surgery. Journal of Thoracic Disease, 5 (6), 638-640. doi: http://doi.org/10.3978/j.issn.2072-1439.2013.11.02

16. Gong, W., Cai, J., Wang, Z., Chen, A., Ye, X., Li, H., Zhao, Q. (2016). Robot-assisted coronary artery bypass grafting improves short-term outcomes compared with minimally invasive direct coronary artery bypass grafting. Journal of Thoracic Disease, 8 (3), 459-468. doi: http://doi.org/10.21037/jtd.2016.02.67

17. Sabashnikov, A., Patil, N. P., Weymann, A., Mohite, P. N., Zych, B., García Sáez, D. et. al. (2014). Outcomes after different non-sternotomy approaches to left single-vessel revascularization: a comparative study with up to 10-year follow-up. European Journal of Cardio-Thoracic Surgery, 46 (4), e48-e55. doi: http://doi.org/10.1093/ejcts/ezu287

18. Yuh, D. D., Vricella, L. A., Baumgartner, W. A. (Eds.) (2007). The Johns Hopkins Manual of Cardiothoracic Surgery. New York: McGraw Hill, 449-467.

19. Zhao, D. F., Edelman, J. J., Seco, M., Bannon, P. G., Wilson, M. K., Byrom, M. J. et. al. (2017). Coronary Artery Bypass Grafting With and Without Manipulation of the Ascending Aorta. Journal of the American College of Cardiology, 69 (8), $924-936$. doi: http://doi.org/10.1016/j.jacc.2016.11.071

20. Albert, A., Ennker, J., Hegazy, Y., Ullrich, S., Petrov, G., Akhyari, P. et. al. (2018). Implementation of the aortic no-touch technique to reduce stroke after off-pump coronary surgery. The Journal of Thoracic and Cardiovascular Surgery, 156 (2), $544-554$. doi: http://doi.org/10.1016/j.jtcvs.2018.02.111

21. McGinn, J. T., Usman, S., Lapierre, H., Pothula, V. R., Mesana, T. G., Ruel, M. (2009). Minimally Invasive Coronary Artery Bypass Grafting: Dual-Center Experience in 450 Consecutive Patients. Circulation, 120(11_suppl_1), S78-S84. doi: http:// doi.org/10.1161/circulationaha.108.840041

22. Nambiar, P., Mittal, C. (2013). Minimally Invasive Coronary Bypass Using Internal Thoracic Arteries via a Left Minithoracotomy. Innovations: Technology and Techniques in Cardiothoracic and Vascular Surgery, 8 (6), 420-426. doi: http://doi.org/ $10.1177 / 155698451300800607$

23. Ziankou, A., Ostrovsky, Y. (2015). Early and Midterm Results of No-Touch Aorta Multivessel Small Thoracotomy Coronary Artery Bypass Grafting: A Propensity Score-Matched Study. Innovations: Technology and Techniques in Cardiothoracic and Vascular Surgery, 10 (4), 258-267. doi: http://doi.org/10.1097/imi.0000000000000185

24. Nambiar, P., Kumar, S., Mittal, C. M., Saksena, K. (2018). Minimally invasive coronary artery bypass grafting with bilateral internal thoracic arteries: Will this be the future? The Journal of Thoracic and Cardiovascular Surgery, 155 (1), 190-197. doi: http:// doi.org/10.1016/j.jtcvs.2017.07.088

25. Harskamp, R. E., Bonatti, J. O., Zhao, D. X., Puskas, J. D., de Winter, R. J., Alexander, J. H., Halkos, M. E. (2014). Standardizing definitions for hybrid coronary revascularization. The Journal of Thoracic and Cardiovascular Surgery, 147 (2), $556-560$. doi: http://doi.org/10.1016/j.jtcvs.2013.10.019

26. Leacche, M., Zhao, D. X., Umakanthan, R., Byrne, J. G. (2012). Do hybrid procedures have proven clinical utility and are they the wave of the future?: hybrid procedures have no proven clinical utility and are not the wave of the future. Circulation, 125 (20), 2504-2510. doi: http://doi.org/10.1161/circulationaha.111.031138

27. Angelini, G., Wilde, P., Salerno, T., Bosco, G., Calafiore, A. (1996). Integrated left small thoracotomy and angioplasty for multivessel coronary artery revascularisation. The Lancet, 347 (9003), 757-758. doi: http://doi.org/10.1016/s01406736(96)90107-5

28. Puskas, J. D., Halkos, M. E., DeRose, J. J., Bagiella, E., Miller, M. A., Overbey, J. et. al. (2016). Hybrid Coronary Revascularization for the Treatment of Multivessel Coronary Artery Disease. Journal of the American College of Cardiology, 68 (4), $356-365$. doi: http://doi.org/10.1016/j.jacc.2016.05.032

29. Tajstra, M., Hrapkowicz, T., Hawranek, M., Filipiak, K., Gierlotka, M., Zembala, M. et. al. (2018). Hybrid Coronary Revascularization in Selected Patients With Multivessel Disease. JACC: Cardiovascular Interventions, 11 (9), 847-852. doi: http://doi.org/ 10.1016/j.jcin.2018.01.271

30. Zhurba, O. O., Rudenko, A. V. (2018). Predictors of intraoperative complications and on-pump conversions of isolated coronary artery bypass grafting in patients with coronary artery disease. Emergency medicine, 7 (94), 19-25. doi http://doi.org/ 10.22141/2224-0586.7.94.2018.150815

31. Mankovskyi, H. B. (2019). Viddaleni rezultaty revaskuliaryzatsii miokarda u patsiientiv z ishemichnoiu khvoroboiu sertsia ta porushenniam vuhlevodnoho obminu. Kyiv: DU «NISSKh im. M. M. Amosova NAMN Ukrainy», 19.

32. Harskamp, R. E., Brennan, J. M., Xian, Y., Halkos, M. E., Puskas, J. D., Thourani, V. H. et. al. (2014). Practice Patterns and Clinical Outcomes After Hybrid Coronary Revascularization in the United States. Circulation, 130 (11), 872-879. doi: http://doi.org/ 10.1161/circulationaha.114.009479

33. Neumann, F.-J., Sousa-Uva, M., Ahlsson, A., Alfonso, F., Banning, A. P., Benedetto, U. et. al. (2018). 2018 ESC/EACTS Guidelines on myocardial revascularization. European Heart Journal, 40 (2), 87-165. doi: http://doi.org/10.1093/eurheartj/ehy394 
34. Chakos, A., Jbara, D., Singh, K., Yan, T. D., Tian, D. H. (2018). Network meta-analysis of antiplatelet therapy following coronary artery bypass grafting (CABG): none versus one versus two antiplatelet agents. Annals of Cardiothoracic Surgery, 7 (5), 577-585. doi: http://doi.org/10.21037/acs.2018.09.02

35. Babliak, O. D., Demianenko, V. M., Melnyk, Ye. A., Revenko, K. A., Pidhaina, L. V., Stohov, O. S. (2018). Maloinvazyvne bahatosudynne koronarne shuntuvannia v umovakh perednolateralnoi torakotomii. Sertse i sudyny. 1 (61), 65-69.

36. Babliak, O. D., Demianenko, V. M., Melnyk, Ye. A., Revenko, K. A., Pidhaina, L. V., Stohov, O. S. (2018). Mini-invazyvne bahatosudynne koronarne shuntuvannia $\mathrm{v}$ umovakh shtuchnoho krovoobihu: analiz rannikh rezultativ ta opanuvannia metodyky. Visnyk sertsevo-sudynnoi khirurhii, 4 (33), 18-21.

Received date 07.08.2020

Accepted date 10.09.2020

Published date 30.09.2020

Oleksandr Pyetkov, PhD, Associate Professor, Department of Surgery of the Heart, Great Vessels and Pediatric Surgery, Kharkiv Medical Academy of Postgraduate Education, Amosova str., 58, Kharkiv, Ukraine, 61176 E-mail: alex.pyetkov@gmail.com

Igor Polivenok, PhD, Head of Department, Department of Interventional Cardiology and Cardiac Intensive Care, State Institution "V. T. Zaycev Institute of General and Urgent Surgery National Academy of Medical Sciences of Ukraine", Balakireva entry, 1, Kharkiv, Ukraine, 61103

E-mail: polivenok@gmail.com

Yuri Skibo, PhD, Head of Department, Department of Surgery of the Heart, Great Vessels and Pediatric Surgery, Kharkiv Medical Academy of Postgraduate Education

Amosova str., 58, Kharkiv, Ukraine, 61176

E-mail: yuri_skibo@ukr.net

Valery Boyko, MD, Professor, Corresponding Member of NAMS of Ukraine, Director, State Institution "V. T. Zaycev Institute of General and Urgent Surgery National Academy of Medical Sciences of Ukraine", Balakireva entry, 1, Kharkiv, Ukraine, 61103

E-mail: igusurg@ukr.net 